Article

\title{
High Electronically Conductive Tungsten Phosphate Glass-Ceramics
}

\author{
Sanja Renka ${ }^{1}$, Teodoro Klaser ${ }^{2}$, Sanja Burazer ${ }^{1}{ }^{\circledR}$, Petr Mošner ${ }^{3}$, Petr Kalenda ${ }^{3}$, \\ Ana Šantić ${ }^{1}$ (D) and Andrea Moguš-Milanković 1,*(D) \\ 1 Division of Materials Chemistry, Ruđer Bošković Institute, 10000 Zagreb, Croatia; \\ sanja.renka@irb.hr (S.R.); Sanja.Burazer@irb.hr (S.B.); asantic@irb.hr (A.Š.) \\ 2 Department of Physics, Faculty of Science, University of Zagreb, 10000 Zagreb, Croatia; \\ tklaser@phy.hr \\ 3 Department of General and Inorganic Chemistry, Faculty of Chemical Technology, \\ University of Pardubice, 53210 Pardubice, Czech Republic; Petr.Mosner@upce.cz (P.M.); \\ Petr.Kalenda2@upce.cz (P.K.) \\ * Correspondence: mogus@irb.hr
}

Received: 19 November 2020; Accepted: 12 December 2020; Published: 15 December 2020

\begin{abstract}
High electronically conductive tungsten phosphate glass-ceramics have been prepared by the controlled crystallization of binary $60 \mathrm{WO}_{3}-40 \mathrm{P}_{2} \mathrm{O}_{5}$ glass in the temperature range from 700 to $935^{\circ} \mathrm{C}$ and for 1 to $24 \mathrm{~h}$. The substantial increase in the conductivity for four orders of magnitude is a result of the formation of electronically conductive $\mathrm{W}_{2} \mathrm{O}_{3}\left(\mathrm{PO}_{4}\right)_{2}$ and $\mathrm{WO}_{3}$ phases. At low crystallization temperature the dominant $\mathrm{W}_{2} \mathrm{O}_{3}\left(\mathrm{PO}_{4}\right)_{2}$ phase is created, whereas at $935^{\circ} \mathrm{C}$ for $24 \mathrm{~h}$ the formation of semiconducting $\mathrm{WO}_{3}$ crystallites of an average size of $80 \mathrm{~nm}$ enhances the conductivity to the highest value of $1.64 \times 10^{-4}(\Omega \mathrm{cm})^{-1}$ at $30^{\circ} \mathrm{C}$. The course of the crystallization and its impact on this exceptionally high electronic transport of binary tungsten phosphate glass-ceramics has been discussed in detail. Since such highly electronically conductive $\mathrm{WO}_{3}$-based glass-ceramics have a great potential as cathode/anode materials in solid state batteries and as electrocatalysts in fuel cells, it is of interest to provide a novel insight into the improvement of their electrical properties.
\end{abstract}

Keywords: binary tungsten phosphate glass-ceramics; crystallization; electronic transport; $\mathrm{W}_{2} \mathrm{O}_{3}\left(\mathrm{PO}_{4}\right)_{2}$ phase; semiconducting $\mathrm{WO}_{3}$ phase

\section{Introduction}

The interest in glass-ceramics has grown exponentially in the recent years due to the novel and useful physical properties that can be obtained by controlling the crystallization process in the glass. Glass-ceramics contain at least one type of functional crystalline phase and a residual glass [1]. The transformation from glass to glass-ceramics takes place by a controlled process of nucleation and crystals growth giving rise to nano- and micro-structures [2]. The physical properties of glass-ceramics are strongly dependent on the size, type, morphology, and distribution of crystalline phases inside the glass matrix, all of which can be tuned by changing the crystallization conditions. For this reason, many functional glass-ceramics with improved mechanical, electrical, magnetic, and optical properties have been developed through the controlled glass crystallization. In particular, a significant scientific effort has been made to develop glass-ceramics which are applicable in the field of electronics and solid-state batteries as electrolytes or cathode/anode materials. However, ionic as well as electronic transport through the glass-ceramic material is by no means simple. Both conduction mechanisms depend on various structural and morphological characteristics of the material. For example, a study by Schirmeisen et al. [3] on lithium-ion conducting silicate glass-ceramics revealed a pivotal role of the 
interfacial regions that act as local electrical short circuits leading to an increase of the ionic conductivity of nanostructured glass-ceramics as compared to the corresponding glass.

Likewise, the electronically conductive oxide glasses containing transition metal oxides such as $\mathrm{WO}_{3}, \mathrm{MoO}_{3}, \mathrm{~V}_{2} \mathrm{O}_{5}$, and $\mathrm{Fe}_{2} \mathrm{O}_{3}$ appear to be versatile materials whose transport properties can be readily tailored by crystallization. In these glasses, electronic conduction occurs by the electron transfer between transition metal ions in different valence states following the small polaron hopping mechanism [4-10]. Expectedly, the crystallization strongly influences the formation of polarons and course of their transport. For instance, Garbarczyk and coworkers performed a series of studies on $\mathrm{V}_{2} \mathrm{O}_{5}-\mathrm{P}_{2} \mathrm{O}_{5}$-based glass-ceramics [11-16] and demonstrated that the polaronic transport can be greatly enhanced by the formation of interfacial regions around nano-crystalline grains. The authors postulated that these interfacial regions have a higher fraction of $\mathrm{V}^{4+}-\mathrm{V}^{5+}$ pairs and form an extensive network of electronic conduction paths which increases polaronic conductivity. On the other hand, our studies on the crystallization of $\mathrm{Fe}_{2} \mathrm{O}_{3}-\mathrm{P}_{2} \mathrm{O}_{5}$-based glasses $[17,18]$ highlight the importance of nature of the phases that crystallize from the glass matrix. By widely varying the temperature and time of the heat-treatments, we were able to assign the changes in the conductivity to the interplay between amorphous glassy phase and crystalline mixed-valent iron and single-valent iron phosphate phases. In these systems, the conductivity decreases in the early stage of nano-crystallization due to the impoverishment of the continuous amorphous phase with $\mathrm{Fe}^{2+}-\mathrm{Fe}^{3+}$ pairs but increases with further formation of the interfacial region along well-defined interconnected crystalline grains.

Considering the crystallization processes in phosphate glasses containing $\mathrm{WO}_{3}$, there are many reports on tungsten oxide-based and tungsten fluorophosphate glass-ceramics, and their structural and optical properties [19-22]. Also, there are several reports on the transport mechanisms of the crystalline monophosphate tungsten bronze of the general formula $\left(\mathrm{PO}_{2}\right)_{4}\left(\mathrm{WO}_{3}\right)_{2 m}$ [23-25] and tungsten oxide, $\mathrm{WO}_{3}$, crystals [26,27]. Recently, Moore et al. [28] revisited highly conductive $\mathrm{WO}_{3}-\mathrm{TiO}_{2}-\mathrm{P}_{2} \mathrm{O}_{5}$ glass-ceramic systems which were first reported by Aitken [26]. They showed that at low crystallization temperature tungsten oxide and titanium pyrophosphate are formed whereas at high temperature $\left(\mathrm{PO}_{2}\right)_{4}\left(\mathrm{WO}_{3}\right)_{2 m}(m=4-7)$ phases are created. Therefore, they concluded that the electrically conducting phases in these glass-ceramics are tungsten phosphates rather than tungsten suboxides reported hitherto.

Most recently, we investigated electrical transport in zinc phosphate glasses which contain alkali [29] and silver [30] oxides in combination with $\mathrm{WO}_{3}$. Our study showed that the exceptionally high electrical conductivity of $\mathrm{WO}_{3}$-rich glasses is a result of the formation of tungsten clusters of $\mathrm{WO}_{6}$ octahedra that facilitate the mobility of polarons. Further, our study on the controlled crystallization of $5 \mathrm{Li}_{2} \mathrm{O}-5 \mathrm{ZnO}-40 \mathrm{P}_{2} \mathrm{O}_{5}-50 \mathrm{WO}_{3}(\mathrm{~mol} \%)$ glass demonstrated that heat-treatments up to $800{ }^{\circ} \mathrm{C}$ induce crystallization of two polymorphs of $\mathrm{W}_{2} \mathrm{O}_{3}\left(\mathrm{PO}_{4}\right)_{2}$ and a minor $\mathrm{W}_{12} \mathrm{P}_{8} \mathrm{O}_{52}$ phase [31]. The conductivity of obtained glass-ceramics is purely polaronic and close in value to that of the parent glass.

The present work aims to investigate the effect of the controlled crystallization on the electrical conductivity of binary $60 \mathrm{WO}_{3}-40 \mathrm{P}_{2} \mathrm{O}_{5}(\mathrm{~mol} \%)$ glass. The crystallization processes were induced by heat-treatments at different temperatures and times which enabled us to prepare glass-ceramics with various amounts of crystalline phases and comprehensively examine their role in electrical transport. According to our best knowledge, this is the first systematic study on the crystallization of binary tungsten phosphate glasses and its role in the enhancement of their transport properties.

\section{Materials and Methods}

The parent glass $60 \mathrm{WO}_{3}-40 \mathrm{P}_{2} \mathrm{O}_{5}(\mathrm{~mol} \%)$ was prepared by a conventional melt-quenching technique using an analytical grade of $\mathrm{H}_{3} \mathrm{PO}_{4}$ and $\mathrm{WO}_{3}$. The mixture of raw materials was firstly homogenized, calcined up to $600{ }^{\circ} \mathrm{C}$, and held for $2 \mathrm{~h}$ in order to remove the water. The reaction mixture was then melted at $1350^{\circ} \mathrm{C}$ in a platinum crucible with a lid and held at that temperature for $20 \mathrm{~min}$. The melt was subsequently poured into a preheated graphite mold and annealed for $2 \mathrm{~h}$ at $515^{\circ} \mathrm{C}$ $\left(5^{\circ} \mathrm{C}\right.$ below $T_{\mathrm{g}}$ ). After cooling to room temperature (RT), the amorphous character of obtained dark blue glass was checked by $\mathrm{X}$-ray diffraction analysis. 
Based on the glass transition temperature $\left(T_{\mathrm{g}}\right)$ and glass crystallization temperature $\left(T_{\mathrm{c}}\right)$, heat-treatment temperatures for induced crystallization of glasses were selected as 700,800 , and $935^{\circ} \mathrm{C}$. The induced crystallization was performed in Nabertherm LHT $04 / 17$ furnace with $10{ }^{\circ} \mathrm{C} / \mathrm{min}$ heating rate and in steady air atmosphere. In the first series of experiments, the powder of $60 \mathrm{WO}_{3}-40 \mathrm{P}_{2} \mathrm{O}_{5}$ glass was pressed in $\sim 0.7 \mathrm{~mm}$ thick pellets and heat-treated for 1 and $6 \mathrm{~h}$ at 700 and $800{ }^{\circ} \mathrm{C}$ and 1,12 , and $24 \mathrm{~h}$ at $935{ }^{\circ} \mathrm{C}$. The obtained glass-ceramics were mechanically strong and their color changed from blue to green with increasing crystallization time and temperature. In order to compare crystallization of the pelleted glass powder and bulk glass, the second set of experiments included the crystallization of $60 \mathrm{WO}_{3}-40 \mathrm{P}_{2} \mathrm{O}_{5}$ glass in the form of $\sim 1 \mathrm{~mm}$ thick discs for 1 and $12 \mathrm{~h}$ at $935^{\circ} \mathrm{C}$. However, the obtained glass-ceramics had much lower mechanical strength and were more prone to cracking in contrast to those prepared from pellets. The as-prepared glass-ceramics were labelled in accordance with their crystallization time and temperature where P and B stand for pellet and bulk crystallization, respectively. For example, P-935-1h glass-ceramic was prepared by heating glass pellet at $935^{\circ} \mathrm{C}$ for $1 \mathrm{~h}$.

X-ray diffraction data was collected at RT on Bruker D8 Discover diffractometer (Bruker AXS $\mathrm{GmbH}$, Karlsruhe, Germany) equipped with LYNXEYE XE-T detector, in Bragg-Brentano geometry. Rietveld structure refinement was performed in HighScore Xpert Plus program 3.0 (Malvern Panalytical, Almelo, Netherlands). Vesta (free crystallographic software available online : https:/jp-minerals.org/ vesta/en/download.html) was used for crystal structure visualization [32]. Refinement was carried out by using the split-type pseudo-Voigt profile function and the polynomial background model. Isotropic vibration modes were assumed for all atoms. During the refinement, a zero shift, scale factor, half-width parameters, asymmetry, and peak shape parameters were simultaneously refined. Microstructural information was also obtained in the course of Rietveld refinement with $\mathrm{LaB}_{6}$ used as instrumental broadening standard.

The microstructure and elemental analysis of the prepared glass-ceramics were studied by field emission scanning electron microscopy FE-SEM JSM 7000 (JEOL, Welwyn Garden City, UK) equipped with the Oxford Instruments EDS/INCA 350 energy dispersive X-ray analyzer (EDS).

The density of the selected glass-ceramic samples, P-935-1h and P-935-24h, was determined at RT by the Archimedes method. Deionized water was used as buoyancy liquid. Measurements were done on three samples of both glass-ceramics and the average density for each glass-ceramic is reported. The random error in the density values was found to be $\pm 1 \%$. The relative density was estimated by comparing the measured density with the theoretical one calculated by the rule of mixtures considering $5.32 \mathrm{~g} / \mathrm{cm}^{3}$ and $7.29 \mathrm{~g} / \mathrm{cm}^{3}$ as the theoretical densities of $\mathrm{W}_{2} \mathrm{O}_{3}\left(\mathrm{PO}_{4}\right)_{2}$ and $\mathrm{WO}_{3}$ phases, respectively.

For the electrical measurements, gold electrodes ( $3.8 \mathrm{~mm}$ diameter) were sputtered on both surfaces of the crystallized samples using the Sputter Coater SC7620 (West Sussex, UK). The samples were subsequently placed between two brass electrodes and the complex impedance was measured using an impedance analyzer (Novocontrol Alpha-AN Dielectric Spectrometer, Hundsangen, Germany) in a wide frequency $\left(0.01 \mathrm{~Hz}-10^{6} \mathrm{~Hz}\right)$ and temperature $\left(-30^{\circ} \mathrm{C}\right.$ to $\left.240^{\circ} \mathrm{C}\right)$ range. The temperature was controlled to an accuracy of $\pm 0.2^{\circ} \mathrm{C}$.

\section{Results and Discussion}

\subsection{Crystallization}

According to the DTA results reported in the previous papers $[29,30,33]$ the temperatures of heat treatments of binary $60 \mathrm{WO}_{3}-40 \mathrm{P}_{2} \mathrm{O}_{5}$ glass were chosen to be in the temperature region above glass transition temperature $\left(T_{\mathrm{g}}=520^{\circ} \mathrm{C}\right)$ at $700{ }^{\circ} \mathrm{C}$ and $800{ }^{\circ} \mathrm{C}$ for 1 and $6 \mathrm{~h}$ and at crystallization temperature $T_{\mathrm{C}}=935^{\circ} \mathrm{C}$ for 1,12 and $24 \mathrm{~h}$. Additionally, samples in the form of discs were heat-treated at $935^{\circ} \mathrm{C}$ for 1 and $12 \mathrm{~h}$ as described in the experimental section. 


\subsection{Structural Characterization}

The temperature-induced evolution of crystalline phases was investigated by the X-ray powder diffraction (XRPD). Figure 1 shows the results of Rietveld refinement analysis for glass pellets heat-treated at 700,800 , and $935^{\circ} \mathrm{C}$ for the time ranging from $1 \mathrm{~h}$ to $24 \mathrm{~h}$.

A wide scattering halo and absence of diffraction lines (Figure 1a,b) indicate that heat treatment at $700{ }^{\circ} \mathrm{C}$, regardless of the heat treatment time, does not induce any crystallization processes and that the P-700 samples are characterized by an amorphous short-range ordering.

a)
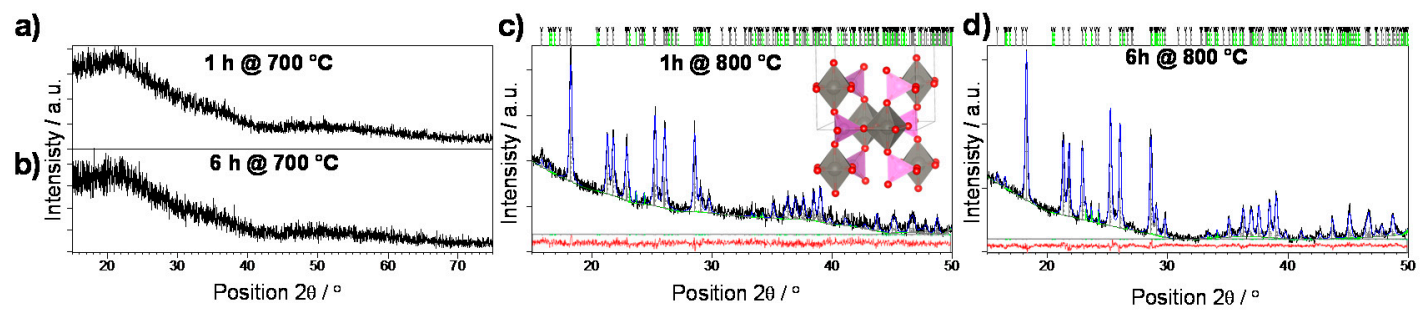

e)

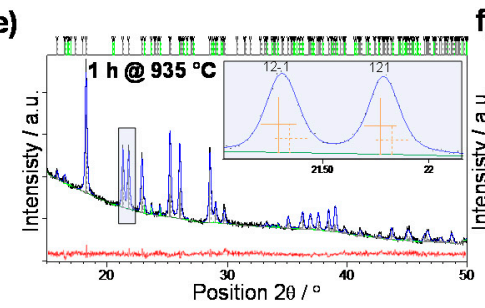

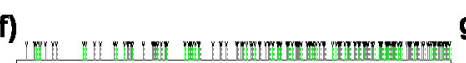

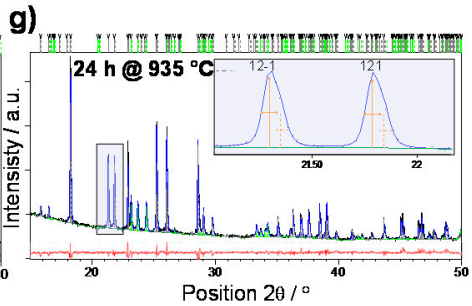

Figure 1. Rietveld refinements of glass pellet samples crystallized for (a) $1 \mathrm{~h}$ at $700{ }^{\circ} \mathrm{C},(\mathbf{b}) 6 \mathrm{~h}$ at $700{ }^{\circ} \mathrm{C}$, (c) $1 \mathrm{~h}$ at $800{ }^{\circ} \mathrm{C},(\mathrm{d}) 6 \mathrm{~h}$ at $800{ }^{\circ} \mathrm{C},(\mathrm{e}) 1 \mathrm{~h}$ at $935^{\circ} \mathrm{C},(\mathrm{f}) 12 \mathrm{~h}$ at $935^{\circ} \mathrm{C}$ and (g) $24 \mathrm{~h}$ at $935^{\circ} \mathrm{C}$. Experimental data are given by black line, the calculated pattern is shown in blue, while the red line represents the difference curve. Grey vertical marks show the positions of diffraction lines belonging to $\mathrm{W}_{2} \mathrm{O}_{3}\left(\mathrm{PO}_{4}\right)_{2}$ phase while the positions of $\mathrm{WO}_{3}$ lines are given as green vertical marks. Inset in (c) shows the structure of dominant phase, $\mathrm{W}_{2} \mathrm{O}_{3}\left(\mathrm{PO}_{4}\right)_{2} ; \mathrm{WO}_{6}$ octahedra are shown in grey while $\mathrm{PO}_{4}$ tetrahedra are pink. The insets in $(\mathbf{e}, \mathbf{g})$ demonstrate the differences in the integral line breadths caused by prolonged crystallization period.

Heat treatment at $800{ }^{\circ} \mathrm{C}$ for $1 \mathrm{~h}$ represents the onset of crystallization with the appearance of diffraction lines corresponding to $\mathrm{W}_{2} \mathrm{O}_{3}\left(\mathrm{PO}_{4}\right)_{2}\left(97.5 w t\right.$. \%) and $\mathrm{WO}_{3}(2.5 w t$. \%) phases. The $\mathrm{W}_{2} \mathrm{O}_{3}\left(\mathrm{PO}_{4}\right)_{2}$ phase crystallizes in the monoclinic system, $\mathrm{P} 2_{1} / m$ space group, with the refined unit-cell parameters: $a=7.796(6) \AA, b=12.526(5) \AA, c=7.777(6) \AA, \beta=92.95(2)^{\circ}$ similar to those reported by Kierkegaard and Asbrink (24072-ICSD) [34]. The structure consists of $\mathrm{W}_{2} \mathrm{O}_{3}$ dimer units (two $\mathrm{WO}_{6}$ octahedra connected in the corner shared manner) surrounded by $\mathrm{PO}_{4}$ tetrahedra (inset in Figure 1c). Each $\mathrm{PO}_{4}$ unit links together four dimer units, also via corner sharing, thus forming the 3D network. From the Figure 1c-g one can observe that monoclinic $\mathrm{W}_{2} \mathrm{O}_{3}\left(\mathrm{PO}_{4}\right)_{2}$ remains the dominant crystalline phase in all the samples (positions of diffraction lines are given as grey vertical marks). However, the pronounced crystallization of $\mathrm{WO}_{3}$ (positions are given as green vertical marks) with a further increase of heat treatment time and temperature is also observed. The $\mathrm{WO}_{3}$ phase also crystallizes in monoclinic system, in space group $\mathrm{P} 2{ }_{1} / c$ with the refined unit-cell parameters: $a=7.317(4) \AA$, $b=7.523(4) \AA, c=10.568(7) \AA, \beta=133.05(2)^{\circ}$ similar to those reported by Tanisaki (17003-ICSD) [35].

Quantitative compositions of the samples heat-treated at 700,800 and $935^{\circ} \mathrm{C}$ for different times of heat treatment are given in Table 1.

Based on the composition of samples given in Table 1, the general trend can be observed; the crystallization of $\mathrm{WO}_{3}$ phase becomes more pronounced with the increment of temperature but also, at both temperatures, prolongation in the heat treatment time results in the increase of $\mathrm{WO}_{3} \mathrm{phase}$ fraction and the decrease in the amount of $\mathrm{W}_{2} \mathrm{O}_{3}\left(\mathrm{PO}_{4}\right)_{2}$ phase. 
Moreover, the X-ray line broadening analysis performed on the P-935-1h and P-935-24h samples revealed the pronounced growth of the diffraction domain sizes of the $\mathrm{W}_{2} \mathrm{O}_{3}\left(\mathrm{PO}_{4}\right)_{2}$ phase with the prolonged time of heat treatment as seen from the evident decrease of integral line breadths for the sample annealed for $24 \mathrm{~h}$ compared to sample annealed for $1 \mathrm{~h}$ in the inset of Figure $1 \mathrm{e}, \mathrm{g}$. On the other hand, the $\mathrm{WO}_{3}$ phase does not show any significant difference in coherent diffraction domains sizes with prolonged heat treatment time; both samples crystallized for $1 \mathrm{~h}$ and $24 \mathrm{~h}$ contain crystallites with average sizes of $\sim 80 \mathrm{~nm}$.

Table 1. Quantitative composition of the samples heat-treated for 1 to $24 \mathrm{~h}$ at 700,800 , and $935{ }^{\circ} \mathrm{C}$.

\begin{tabular}{ccccc}
\hline \multirow{2}{*}{ Sample } & \multicolumn{2}{c}{ Heat Treatment Conditions } & \multicolumn{2}{c}{ Composition (in $w t . \%)$} \\
\cline { 2 - 5 } & $\mathbf{T} /{ }^{\circ} \mathbf{C}$ & $\boldsymbol{t} / \mathbf{h}$ & $\mathbf{W}_{\mathbf{2}} \mathbf{O}_{\mathbf{3}}\left(\mathbf{P O}_{\mathbf{4}} \mathbf{~}_{\mathbf{2}}\right.$ & $\mathbf{W O}_{\mathbf{3}}$ \\
\hline $\mathrm{P}{ }^{*}-700-1 \mathrm{~h}$ & 700 & 1 & - & - \\
$\mathrm{P}-700-6 \mathrm{~h}$ & 700 & 6 & - & - \\
$\mathrm{P}-800-1 \mathrm{~h}$ & 800 & 1 & $97.5(1)$ & $2.5(1)$ \\
$\mathrm{P}-800-6 \mathrm{~h}$ & 800 & 6 & $96.0(2)$ & $4.0(1)$ \\
$\mathrm{P}-935-1 \mathrm{~h}$ & 935 & 1 & $95.7(2)$ & $4.3(1)$ \\
$\mathrm{P}-935-12 \mathrm{~h}$ & 935 & 12 & $90.9(1)$ & $9.1(1)$ \\
$\mathrm{P}-935-24 \mathrm{~h}$ & 935 & 24 & $82.0(1)$ & $18.0(2)$ \\
$\mathrm{B}$ *935-1h & 935 & 1 & $76.1(2)$ (orthorombic) & $4.8(2)$ \\
$\mathrm{B}-935-12 \mathrm{~h}$ & 935 & 12 & $19.1(2)$ (monoclinic) & $8.2(1)$ \\
\hline${ }^{*}$ Labels P and B denote crystallization from pellet and bulk (discs), respectively.
\end{tabular}

The crystallization from bulk samples have also been investigated by the means of quantitative Rietveld refinement as shown in Figure 2.
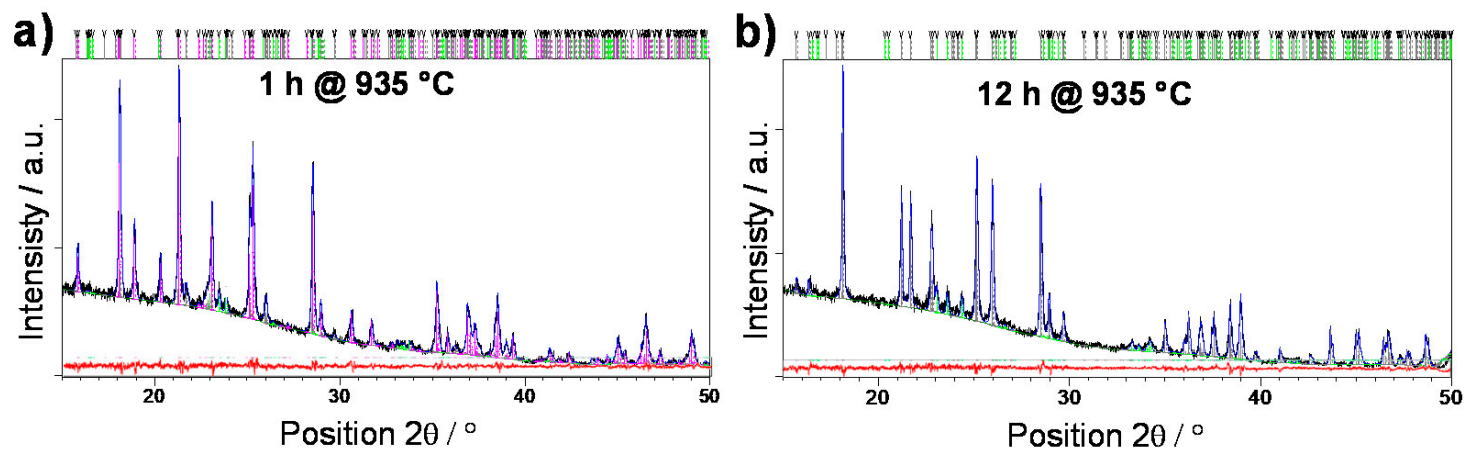

Figure 2. Rietveld refinements of the bulk glass samples crystallized for (a) $1 \mathrm{~h}$ and (b) $12 \mathrm{~h}$ at $935^{\circ} \mathrm{C}$. Experimental data are given by black line, the calculated pattern is shown in blue, while the red line represents the difference curve. Grey vertical marks show the positions of diffraction lines belonging to monoclinic $\mathrm{W}_{2} \mathrm{O}_{3}\left(\mathrm{PO}_{4}\right)_{2}$ phase, magenta bars represent reflection of orthorhombic $\mathrm{W}_{2} \mathrm{O}_{3}\left(\mathrm{PO}_{4}\right)_{2}$ phase, while the positions of $\mathrm{WO}_{3}$ lines are given as green vertical marks.

Interestingly, unlike the sample obtained from pellets, the sample obtained from bulk, when heat-treated at $935^{\circ} \mathrm{C}$ for $1 \mathrm{~h}$, shows the dominant presence of orthorhombic $\mathrm{W}_{2} \mathrm{O}_{3}\left(\mathrm{PO}_{4}\right)_{2}$ phase as reported by Hanawa and Imoto (50742-ICSD) [36], accompanied by monoclinic $\mathrm{W}_{2} \mathrm{O}_{3}\left(\mathrm{PO}_{4}\right)_{2}$ phase as well as small amount of $\mathrm{WO}_{3}$. With increase in heat treatment time, a polymorphic transition from orthorhombic to monoclinic phase $\mathrm{W}_{2} \mathrm{O}_{3}\left(\mathrm{PO}_{4}\right)_{2}$ is observed, together with increase in the fraction of $\mathrm{WO}_{3}$ phase. The presence of the mixture of $\mathrm{W}_{2} \mathrm{O}_{3}\left(\mathrm{PO}_{4}\right)_{2}$ polymorphs in B-935-1h indicates the difference in crystallization processes which occur within the bulk and surface of the glass. It seems that orthorhombic $\mathrm{W}_{2} \mathrm{O}_{3}\left(\mathrm{PO}_{4}\right)_{2}$ starts to crystallize from the bulk and as crystallization proceeds it transforms to a monoclinic phase. This is in accordance with our study of crystallization of $5 \mathrm{Li}_{2} \mathrm{O}-5 \mathrm{ZnO}-40 \mathrm{P}_{2} \mathrm{O}_{5}-50 \mathrm{WO}_{3}(\mathrm{~mol} \%)$ glass where the heat treatments of the glass in the form of disc at $800{ }^{\circ} \mathrm{C}$ for 1 and $6 \mathrm{~h}$ also resulted in glass-ceramics containing both $\mathrm{W}_{2} \mathrm{O}_{3}\left(\mathrm{PO}_{4}\right)_{2}$ polymorphs [31]. 


\section{SEM Analysis}

The insight into the microstructural features of glass-ceramics and crystalline grains was gained using scanning electron microscopy (SEM). Figure 3 exhibits the SEM micrographs of tungsten phosphate glass-ceramics obtained at various temperatures and for different times.

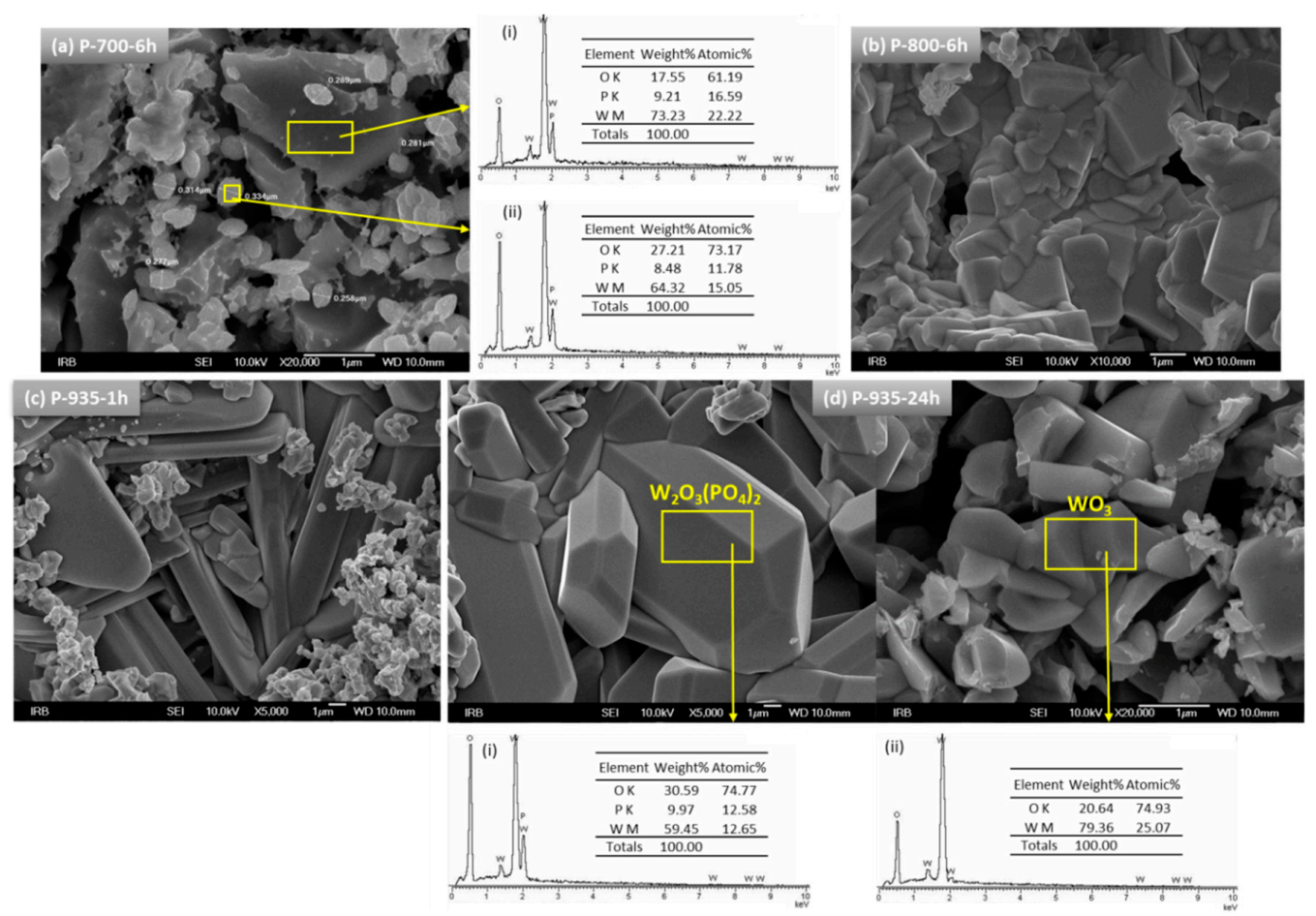

Figure 3. SEM micrographs of glass-ceramics prepared at (a) $700{ }^{\circ} \mathrm{C}$ for $6 \mathrm{~h},(\mathbf{b}) 800{ }^{\circ} \mathrm{C}$ for $6 \mathrm{~h}$, (c) $935^{\circ} \mathrm{C}$ for $1 \mathrm{~h}$, and (d) $935^{\circ} \mathrm{C}$ for $24 \mathrm{~h}$. EDS spectra and tables with chemical composition from selected areas of the samples are shown in the insets (i) and (ii).

From Figure 3a, it can be seen that the P-700-6h sample contains grains of different sizes with no defined morphology. The EDS analysis shows that the chemical composition of the large grains corresponds to that of the parent glass, whereas smaller particles having relatively narrow size distribution of $\sim 0.30 \mu \mathrm{m}$ are stoichiometrically close to $\mathrm{W}_{2} \mathrm{O}_{3}\left(\mathrm{PO}_{4}\right)_{2}$ phase, see tables in the upper-middle panel in Figure 3. Considering that the PXRD data do not show any diffraction lines it can be assumed that the small grains are amorphous, and, in fact, they act as precursors for further crystallization of $\mathrm{W}_{2} \mathrm{O}_{3}\left(\mathrm{PO}_{4}\right)_{2}$ crystals.

At higher heat treatment temperature, namely $800{ }^{\circ} \mathrm{C}$ for $6 \mathrm{~h}$, the microstructure shows better-defined grains with sharp edges and apexes which, according to PXRD, can be identified as dominant $\mathrm{W}_{2} \mathrm{O}_{3}\left(\mathrm{PO}_{4}\right)_{2}$ phase. Also, large, elongated crystals, prismatic in shape, which appeared after crystallization at $935^{\circ} \mathrm{C}$ for $1 \mathrm{~h}$, are identified as $\mathrm{W}_{2} \mathrm{O}_{3}\left(\mathrm{PO}_{4}\right)_{2}$ phase, see Figure $3 \mathrm{c}$. When heat treatment at $935^{\circ} \mathrm{C}$ is prolonged to $24 \mathrm{~h}$, the $\mathrm{W}_{2} \mathrm{O}_{3}\left(\mathrm{PO}_{4}\right)_{2}$ phase grows in size into large regular crystals of perfectly formed prismatic habit, Figure $3 \mathrm{~d}$. In accordance with PXRD results, this sample also contains sporadically distributed small grains of an irregular shape whose chemical composition matches $\mathrm{WO}_{3}$ phase, see EDS spectrum and table in the lower panel in Figure $3 \mathrm{~d}$. The size of $\mathrm{WO}_{3}$ grains is approximately $\sim 1 \mu \mathrm{m}$, however, the $\mathrm{X}$-ray line broadening analysis revealed that the crystallites within the grains have the average size of $\sim 80 \mathrm{~nm}$.

Noteworthy, the experimental densities of P-935-1h and P-935-24h glass-ceramics are significantly smaller than the corresponding theoretical values, P-935- $1 \mathrm{~h}: \rho_{\text {exp }}=4.43 \mathrm{~g} / \mathrm{cm}^{3}$ vs. $\rho_{\text {theo }}=5.37 \mathrm{~g} / \mathrm{cm}^{3}$ and P-935-24h: $\rho_{\text {exp }}=4.68 \mathrm{~g} / \mathrm{cm}^{3}$ vs. $\rho_{\text {theo }}=5.58 \mathrm{~g} / \mathrm{cm}^{3}$, giving the relative densities of $82 \%$ and $84 \%$, 
respectively. This indicates high porosity of the obtained glass-ceramics which is in line with the SEM micrographs shown in Figure 3c,d.

\subsection{Electrical Transport}

The conductivity spectra for P-935-1h glass-ceramics, as typical spectra for all samples in this study, is shown in Figure 4. Each isotherm exhibits a frequency-independent conductivity (DC conductivity) over a wide frequency range and a small frequency-dependent part at highest frequencies. These spectral features are characteristic for the electronically conducting materials and indicate fast non-localized electronic transport over a broad range of frequencies and temperatures. According to the PXRD analysis and SEM micrographs, samples heat-treated at $700{ }^{\circ} \mathrm{C}$ for 1 and $6 \mathrm{~h}$ show an amorphous structure with an indication of the stoichiometric rearrangement within the glassy phase whereas at higher crystallization temperatures, 800 and $935^{\circ} \mathrm{C}$, the crystallization processes rise creating two crystalline phases: $\mathrm{W}_{2} \mathrm{O}_{3}\left(\mathrm{PO}_{4}\right)_{2}$ and $\mathrm{WO}_{3}$. Interestingly though, all samples, regardless of their structural and morphological properties, show frequency-independent conductivity over almost entire frequency span which signifies the absence of any blocking effects of the grain boundaries and (crystalline) grains to the conduction process. These effects usually manifest as a characteristic decrease of conductivity at lower frequencies and a corresponding low-frequency plateau. Therefore, it can be concluded that the electronic transport in all prepared glass-ceramics is continuous and uninterrupted.

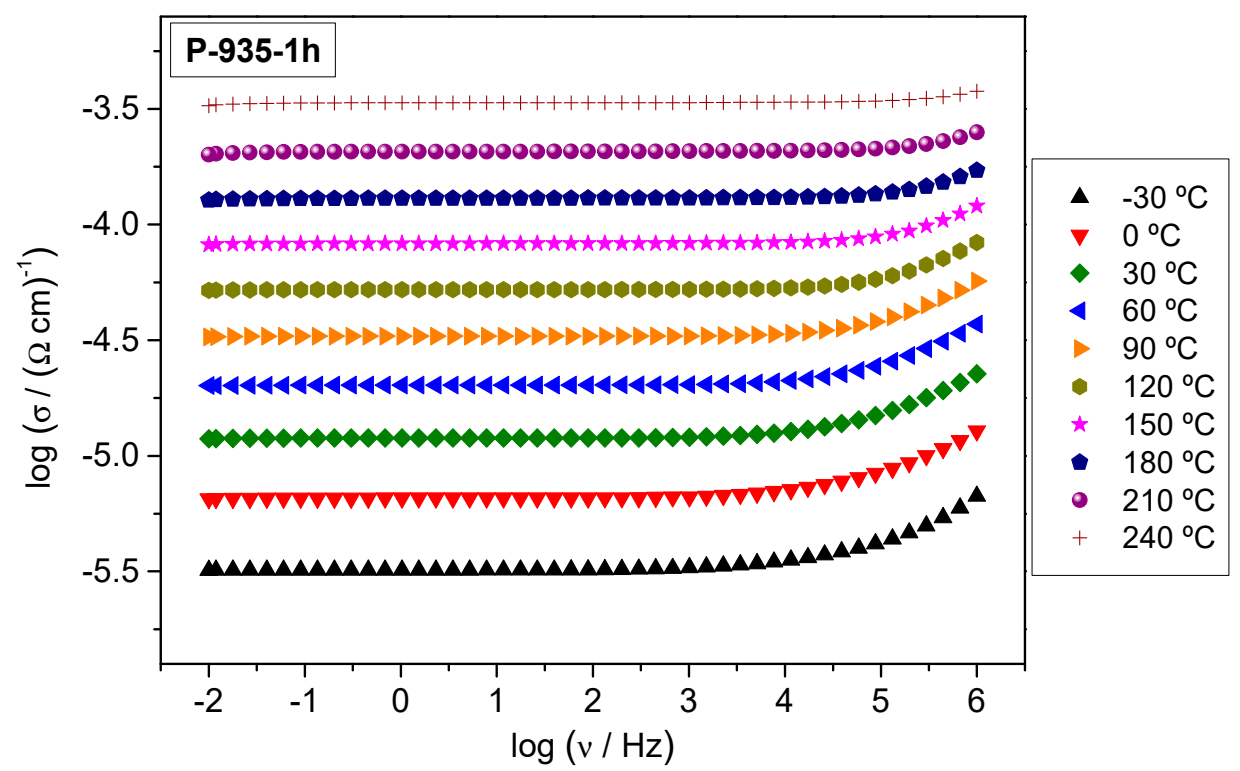

Figure 4. Conductivity spectra at different temperatures of glass-ceramics prepared at $935^{\circ} \mathrm{C}$ for $1 \mathrm{~h}$.

For all samples, the DC conductivity exhibits Arrhenius temperature dependence and hence has characteristic activation energy, see Figure $5 \mathrm{a}$. The activation energy for DC conductivity, $E_{\mathrm{DC}}$, for each sample was determined from the slope of $\log \left(\sigma_{\mathrm{DC}} T\right)$ vs. 1000/T using the equation $\sigma_{\mathrm{DC}} T=\sigma_{0} \exp \left(-E_{\mathrm{DC}} / \mathrm{k}_{\mathrm{B}} T\right)$, where $\sigma_{\mathrm{DC}}$ is the conductivity, $\sigma_{0}$ is the pre-exponential factor, $E_{\mathrm{DC}}$ is the activation energy, $\mathrm{k}_{\mathrm{B}}$ is the Boltzmann constant, and $T$ is the temperature $(\mathrm{K})$. The DC conductivity at $30^{\circ} \mathrm{C}$ and determined activation energy, $E_{\mathrm{DC}}$, for the parent glass and all glass-ceramics are displayed in Table 2. 
Table 2. DC conductivity, $\sigma_{\mathrm{DC}}$, at $30{ }^{\circ} \mathrm{C}$ and activation energy, $E_{\mathrm{DC}}$, for parent $60 \mathrm{WO}_{3}-40 \mathrm{P}_{2} \mathrm{O}_{5}$ bulk glass and prepared glass-ceramics.

\begin{tabular}{ccc}
\hline Sample & $\sigma_{\mathrm{DC}} /(\mathbf{\Omega} \mathbf{~ c m})^{\mathbf{- 1}}$ at $\mathbf{3 0}^{\circ} \mathbf{C} \pm \mathbf{1 . 0} \%$ & $E_{\mathrm{DC}} / \mathbf{e V} \pm \mathbf{1 . 0 \%}$ \\
\hline B-Glass & $4.26 \times 10^{-6}$ & 0.37 \\
P-700-1h & $3.18 \times 10^{-8}$ & 0.35 \\
P-700-6h & $6.57 \times 10^{-8}$ & 0.35 \\
P-800-1h & $3.11 \times 10^{-6}$ & 0.30 \\
P-800-6h & $2.38 \times 10^{-6}$ & 0.29 \\
P-935-1h & $1.20 \times 10^{-5}$ & 0.18 \\
P-935-12h & $5.26 \times 10^{-5}$ & 0.13 \\
P-935-24h & $1.64 \times 10^{-4}$ & 0.17 \\
B-935-1h & $1.19 \times 10^{-5}$ & 0.29 \\
B-935-12h & $2.14 \times 10^{-5}$ & 0.27 \\
\hline
\end{tabular}
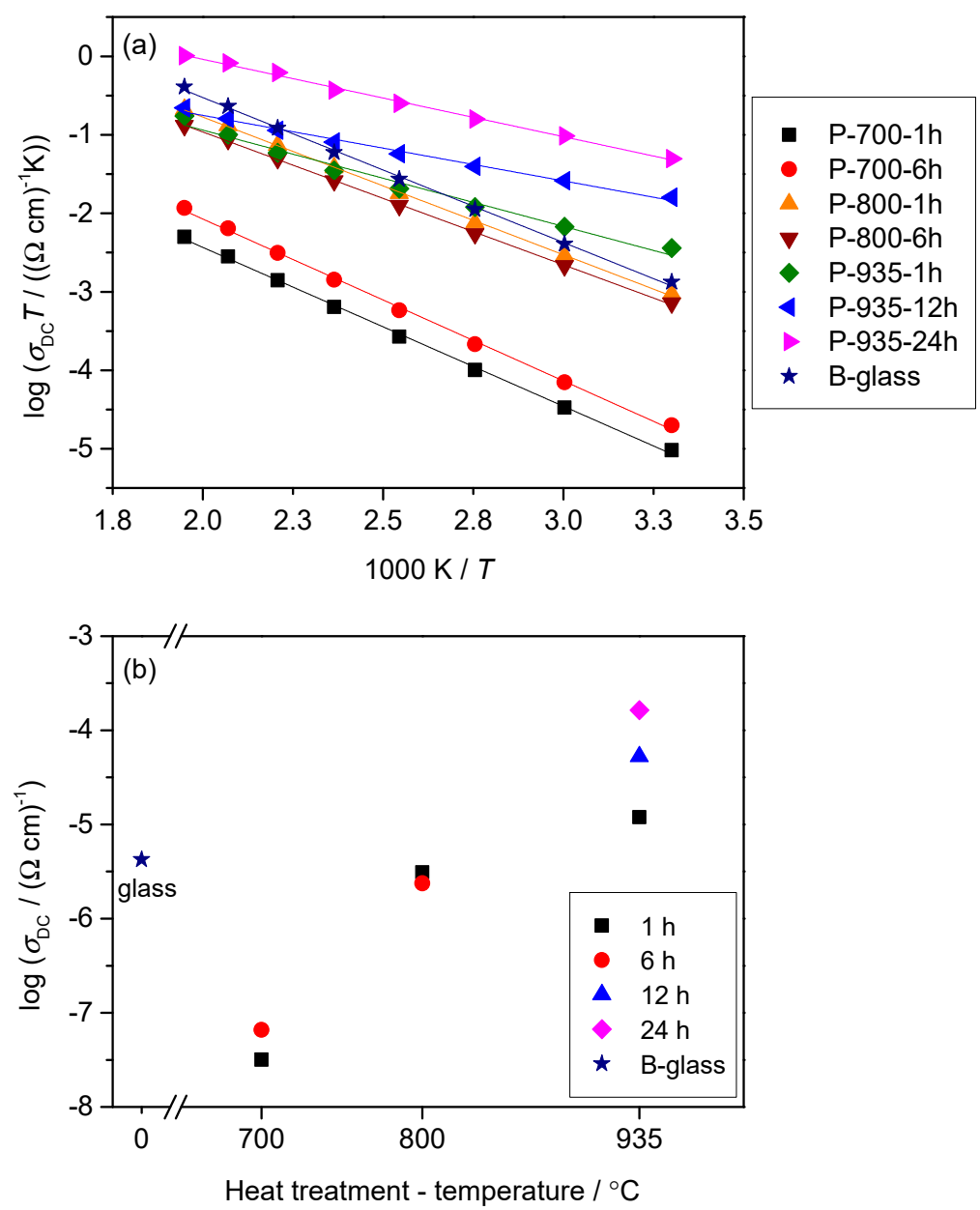

Figure 5. (a) Arrhenius plot of the parent $60 \mathrm{WO}_{3}-40 \mathrm{P}_{2} \mathrm{O}_{5}$ glass and glass-ceramics prepared from pellets and (b) their DC conductivity, $\sigma_{\mathrm{DC}}$, at $30^{\circ} \mathrm{C}$ as a function of crystallization temperature and time. The error bars are at most of the order of the symbol size.

In Figure $5 b$, the dependence of $\sigma_{\mathrm{DC}}$ on the heat treatment conditions shows changes over four orders of magnitude which are correlated to the induced (micro)structural modifications.

As can be seen from Figure $5 \mathrm{~b}$, the heat treatments at $700{ }^{\circ} \mathrm{C}$ for 1 and $6 \mathrm{~h}$ result in nearly two orders of magnitude lower DC conductivity $\left(\sigma_{\mathrm{DC}}=6.57 \times 10^{-8}(\Omega \mathrm{cm})^{-1}\right.$ for P-700-6h at $\left.30^{\circ} \mathrm{C}\right)$, than the starting bulk glass $\left(\sigma_{\mathrm{DC}}=4.26 \times 10^{-6}(\Omega \mathrm{cm})^{-1}\right.$ at $\left.30^{\circ} \mathrm{C}\right)$. At this point, it is important to consider the structure and electrical transport within the parent bulk glass itself. Our recent studies [29,30] show that the exceptionally high DC conductivity of binary $60 \mathrm{WO}_{3}-40 \mathrm{P}_{2} \mathrm{O}_{5}$ glass is a result of the formation of 
tungsten clusters of $\mathrm{WO}_{6}$ octahedra which facilitate the mobility of polarons via $\mathrm{W}^{5+}-\mathrm{O}-\mathrm{W}^{6+}-\mathrm{O}-\mathrm{W}^{5+}$ bonds. Remarkably, in tungsten phosphate glasses the most important factor of polaronic transport is found to be the structure of the glass network and not the fraction of reduced tungsten, $\mathrm{W}^{5+}$ ions $[29,30]$. Considering the high conductivity in starting $60 \mathrm{WO}_{3}-40 \mathrm{P}_{2} \mathrm{O}_{5}$ bulk glass as a result of an easy motion of polarons through the tungsten clusters, it seems that the lower DC conductivity of P-700-1h and P-700-6h samples is related to a subtle rearrangement of the glass network during heating which accompanies breaking of the bonds in the tungsten clusters and formation of two fully amorphous but stoichiometrically different phases as shown by PXRD and SEM-EDS analysis, see Figure 1a,b and Figure 3a.

As the crystallization progresses and crystalline $\mathrm{W}_{2} \mathrm{O}_{3}\left(\mathrm{PO}_{4}\right)_{2}$ and $\mathrm{WO}_{3}$ phases appear, the DC conductivity sharply increases to $3.11 \times 10^{-6}(\Omega \mathrm{cm})^{-1}$ and $2.38 \times 10^{-6}(\Omega \mathrm{cm})^{-1}$ at $30{ }^{\circ} \mathrm{C}$ for P-800-1h and P-800-6h samples, respectively. From the Rietveld analysis, it is evident that the $\mathrm{W}_{2} \mathrm{O}_{3}\left(\mathrm{PO}_{4}\right)_{2}$ crystalline phase dominates in both samples having the relative proportion of $97.5 \mathrm{wt} . \%(\mathrm{P}-800-1 \mathrm{~h})$ and 96.0 wt. \% (P-800-6h), see Table 1. Also, the SEM micrograph of P-800-6h shows compact microstructure with well-connected crystalline grains which suggests that the observed increase in conductivity, in comparison to amorphous P-700-1h and P700-6h, is related to the fast electron transport within and/or along $\mathrm{W}_{2} \mathrm{O}_{3}\left(\mathrm{PO}_{4}\right)_{2}$ grains. This agrees well with our recent investigation of the effect of the induced crystallization on the electrical conductivity of polaronic $5 \mathrm{Li}_{2} \mathrm{O}-5 \mathrm{ZnO}-40 \mathrm{P}_{2} \mathrm{O}_{5}-50 \mathrm{WO}_{3}(\mathrm{~mol} \%)$ glass [31] where we showed that crystallization of monoclinic and orthorhombic $\mathrm{W}_{2} \mathrm{O}_{3}\left(\mathrm{PO}_{4}\right)_{2}$ as dominant phases in these glass-ceramics keeps the conductivity nearly the same as for the parent glass.

For glass-ceramics heat-treated at $935{ }^{\circ} \mathrm{C}$ for various times the DC conductivity increases further reaching the values of $\sigma_{\mathrm{DC}}=1.20 \times 10^{-5}(\Omega \mathrm{cm})^{-1}, \sigma_{\mathrm{DC}}=5.26 \times 10^{-5}(\Omega \mathrm{cm})^{-1}$, and $\sigma_{\mathrm{DC}}=1.64 \times 10^{-4}(\Omega \mathrm{cm})^{-1}$ at $30^{\circ} \mathrm{C}$ for P-935-1h, P-935-12h, and P-935-24h samples, respectively, see Table 2. According to the Rietveld analysis in these glass-ceramics, the relative amount of $\mathrm{WO}_{3}$ increases gradually from $4.3 w t$. \% for P-935-1h to $9.1 w t$. \% for P-935-12h and $18.0 w t$. \% for P-935-24h glass-ceramics, see Table 1. In line with the PXRD results, the SEM micrographs shown in Figure $3 c$, reveal long prismatic crystals that correspond to the $\mathrm{W}_{2} \mathrm{O}_{3}\left(\mathrm{PO}_{4}\right)_{2}$ in the microstructure of $\mathrm{P}-935-1 \mathrm{~h}$ whereas as crystallization proceeds with prolonged heating time to $24 \mathrm{~h}$, along with the large $\mathrm{W}_{2} \mathrm{O}_{3}\left(\mathrm{PO}_{4}\right)_{2}$ crystals, agglomerates of $\mathrm{WO}_{3}$ crystallites are evidenced, see Figure $3 \mathrm{~d}$. Here, it is worth noting that the $\mathrm{X}$-ray line broadening analysis revealed that the size of $\mathrm{WO}_{3}$ crystallites within the grains does not change with the heat treatment time and remains app. $\sim 80 \mathrm{~nm}$ in all glass-ceramics. Also, the relative density of P-935-1h and P-935-24h glass-ceramics is nearly the same (82-84\%), indicating similar porosity and volume fraction of grain boundaries in both samples. Since the DC conductivity systematically increases with prolonged time of the heat treatment it can be concluded that the increase in the amount of nanostructured $\mathrm{WO}_{3}$ crystallites in these glass-ceramics is responsible for the observed rise of DC conductivity.

Let us now consider $\mathrm{WO}_{3}$ crystals. It is well known that $\mathrm{WO}_{3}$ is an n-type semiconductor with a wide band gap [37-39]. It undergoes several phase transitions as a function of temperature, with the monoclinic polymorph being stable at room temperature as also shown by our PXRD results. The electron concentration in $\mathrm{WO}_{3}$ is determined mainly by the concentration of stoichiometric defects such as oxygen vacancies which generate a new energy level below the conduction band. At the generated energy level, the active electrons can be transited to the upper energy levels. The conduction band generates free electrons and $\mathrm{WO}_{3}$ is thus electronically conductive [38,39]. Therefore, with increasing relative amount of $\mathrm{WO}_{3}$ crystallites in the P-935 glass-ceramics the concentration of free electrons also increases leading to the enhancement in DC conductivity. The obtained high DC conductivity, $\sigma_{\mathrm{DC}}=1.64 \times 10^{-4}(\Omega \mathrm{cm})^{-1}$ at $30^{\circ} \mathrm{C}$ for P-935-24h glass-ceramics, clearly reveals a rapid electron transport through $\mathrm{WO}_{3}$ crystallites as well as electronically conductive $\mathrm{W}_{2} \mathrm{O}_{3}\left(\mathrm{PO}_{4}\right)_{2}$ crystals, resulting in high electronic conductivity.

Further, we analyze the electrical conductivity of the glass-ceramics prepared from the bulk and compare them with those prepared from the pellet. Figure 6 shows the frequency dependence of 
conductivity for the bulk and pellet samples heat-treated at $935^{\circ} \mathrm{C}$ for 1 and $12 \mathrm{~h}$. As can be seen from Figure 6a the electrical conductivity for both, P-935-1h and B-935-1h samples, shows the same values, $\sigma_{\mathrm{DC}}=1.20 \times 10^{-5}(\Omega \mathrm{cm})^{-1}$ and $\sigma_{\mathrm{DC}}=1.19 \times 10^{-5}(\Omega \mathrm{cm})^{-1}$ at $30^{\circ} \mathrm{C}$, respectively. The PXRD analysis shows that the bulk sample heat-treated for $1 \mathrm{~h}$ exhibits an orthorhombic $\mathrm{W}_{2} \mathrm{O}_{3}\left(\mathrm{PO}_{4}\right)_{2}$ as a dominant phase along with monoclinic $\mathrm{W}_{2} \mathrm{O}_{3}\left(\mathrm{PO}_{4}\right)_{2}$ phase and some traces of $\mathrm{WO}_{3}$. Structurally, these two $\mathrm{W}_{2} \mathrm{O}_{3}\left(\mathrm{PO}_{4}\right)_{2}$ polymorphs do not differ substantially, so nearly identical values for the DC conductivity are expected. A slight decrease in the DC conductivity of bulk glass-ceramic crystallized for $12 \mathrm{~h}$ if compared with that prepared from the pellet, see Figure $6 \mathrm{~b}$, is a result of a slightly smaller amount of $\mathrm{WO}_{3}(8.2 \mathrm{wt}$. \% for B-935-12h vs. $9.1 \mathrm{wt}$. \% for P-935-12h) as well as a decrease in the crystals connectivity within the microstructure. In fact, glass-ceramics prepared from the bulk glass were very fragile and much less dense than their counterparts prepared from the pellets which implies that their conduction pathways are reduced and hence electron transport slower.
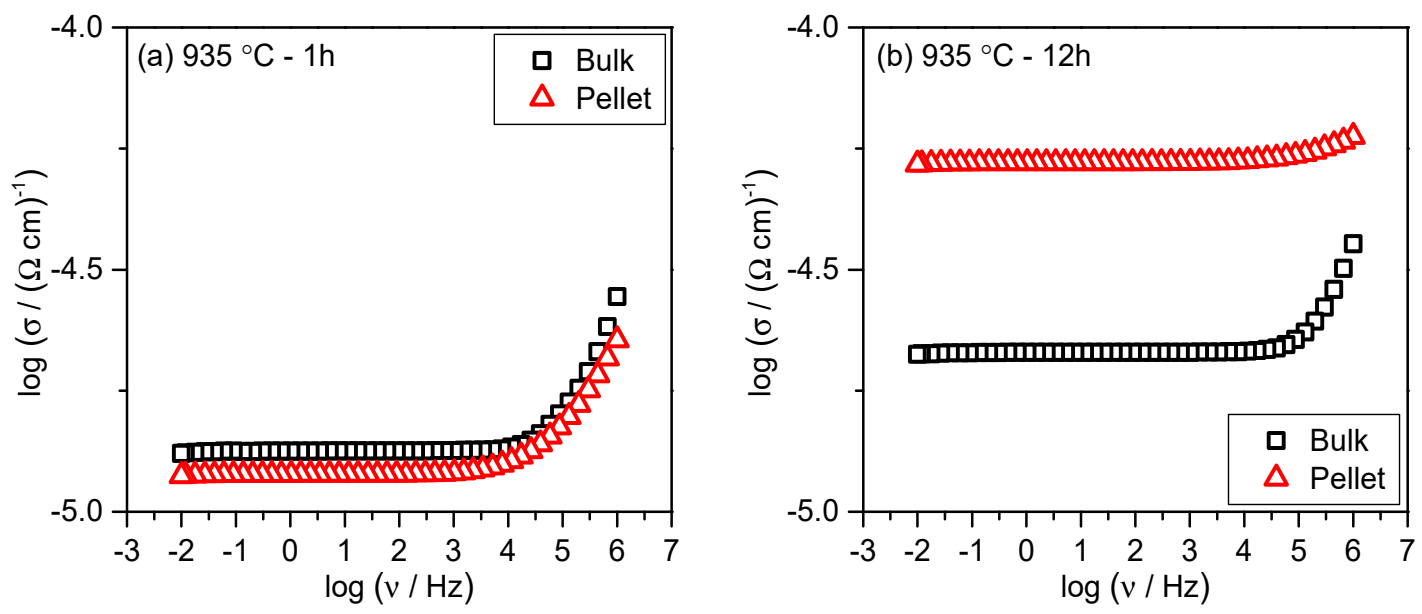

Figure 6. Comparison of the conductivity spectra measured at $30^{\circ} \mathrm{C}$ for glass-ceramics prepared from the bulk glass (black squares) and pelleted glass powder (red triangles) at $935^{\circ} \mathrm{C}$ for (a) $1 \mathrm{~h}$ and (b) $12 \mathrm{~h}$.

The analysis of the activation energy, $E_{\mathrm{DC}}$, for all samples shows an opposite trend to the DC conductivity, implying that the changes in microstructure have an impact on the activation energy. Also, a continuous decrease in the activation energy from $0.35 \mathrm{eV}$ for P-700- $1 \mathrm{~h} \mathrm{to} 0.17 \mathrm{eV}$ for P-935-24h corresponds well to the previously reported data $[40,41]$ for the n-type semiconductor behavior of $\mathrm{WO}_{3}$. Thus, the low activation energy of P-935 glass-ceramics acts as a facilitating factor in easy conductive pathways through the crystalline $\mathrm{WO}_{3}$ and $\mathrm{W}_{2} \mathrm{O}_{3}\left(\mathrm{PO}_{4}\right)_{2}$ phases. On the other hand, the slightly higher activation energy for B-935- $1 \mathrm{~h}$ and B-935-12h glass-ceramics of $0.29 \mathrm{eV}$ and $0.27 \mathrm{eV}$, mirrors a less compact microstructural network of the bulk samples.

\section{Conclusions}

A series of novel electronically conductive glass-ceramics were prepared by heat treatments of polaronic $60 \mathrm{WO}_{3}-40 \mathrm{P}_{2} \mathrm{O}_{5}(\mathrm{~mol} \%)$ glasses at different temperatures $\left(700,800\right.$, and $\left.935^{\circ} \mathrm{C}\right)$ and for various times $(1,6,12$, and $24 \mathrm{~h})$. For glasses heat-treated at $700{ }^{\circ} \mathrm{C}$ for 1 and $6 \mathrm{~h}$ PXRD measurements show fully amorphous structure, however SEM-EDS micrographs reveal the presence of two types of grains; the large ones with the composition of the parent glass and the small ones which act as precursors for crystallization of $\mathrm{W}_{2} \mathrm{O}_{3}\left(\mathrm{PO}_{4}\right)_{2}$. The heat treatments at higher temperatures induce the crystallization of $\mathrm{W}_{2} \mathrm{O}_{3}\left(\mathrm{PO}_{4}\right)_{2}$ as a dominant phase and minor $\mathrm{WO}_{3}$ phase in all glass-ceramics. The amount of $\mathrm{WO}_{3}$ increases with increasing heat treatment temperature and time and reaches the highest value of $18.0 \mathrm{wt} . \%$ for the glass-ceramics prepared at $935^{\circ} \mathrm{C}$ for $24 \mathrm{~h}$. The electrical conductivity of prepared glass-ceramics is electronic in nature and shows a strong dependence on the evolution of crystalline phases. While the samples prepared at $700{ }^{\circ} \mathrm{C}$ have two orders of magnitude lower conductivity than 
the parent bulk glass due to the breakage of the tungsten clusters in glass network, the fast electronic transport within the $\mathrm{W}_{2} \mathrm{O}_{3}\left(\mathrm{PO}_{4}\right)_{2}$ and $\mathrm{WO}_{3}$ crystalline grains makes glass-ceramics prepared at higher temperatures highly conductive. In particular, the increase of the amount of semiconducting $\mathrm{WO}_{3}$ crystallites of an average size of $\sim 80 \mathrm{~nm}$ enhances the conduction of the glass-ceramics to the order of $\sim 10^{-4}(\Omega \mathrm{cm})^{-1}$ at $30^{\circ} \mathrm{C}$.

Author Contributions: Conceptualization, A.Š., A.M.-M.; methodology, A.Š. and S.R.; software, S.B. and T.K.; validation, A.Š.; formal analysis, S.R., T.K. and P.K.; investigation, A.Š., S.R. and P.M.; resources, A.Š. and P.M.; data curation, S.R.; writing-original draft preparation, A.Š., S.R. and A.M.-M.; writing-review and editing, A.Š. and A.M.-M.; visualization, A.Š. and S.R.; supervision, A.Š. and A.M.-M.; project administration, A.Š.; funding acquisition, A.Š. All authors have read and agreed to the published version of the manuscript.

Funding: This research was funded by Hrvatska zaklada za znanost (Croatian Science Foundation), POLAR-ION-GLASS project, grant number IP-2018-01-5425. Czech authors P.M. and P.K. are grateful for the financial support from the Grant Agency of the Czech Republic (Grant No. 18-01976S).

Conflicts of Interest: The authors declare no conflict of interest.

\section{References}

1. Deubener, J.; Allix, M.; Davis, M.J.; Duran, A.; Höche, T.; Honma, T.; Komatsu, T.; Krüger, S.; Mitra, I.; Müller, R.; et al. Updated definition of glass-ceramics. J. Non-Cryst. Solids 2018, 501, 3-10. [CrossRef]

2. Zanotto, E.D. Bright future for glass-ceramics. J. Non-Cryst. Solids 2018, 501, 3-10.

3. Schirmeisen, A.; Taskiran, A.; Fuchs, H.; Bracht, H.; Murugavel, S.; Roling, B. Fast Interfacial Ionic Conduction in Nanostructured Glass Ceramics. Phys. Rev. Lett. 2007, 98, 225901-225904. [CrossRef] [PubMed]

4. Sayer, M.; Mansingh, A. Transport properties of semiconducting phosphate glasses. Phys. Rev. B 1972, 6, 4629. [CrossRef]

5. Mott, N.F. Conduction in glasses containing transition metal ions. J. Non-Cryst. Solids 1968, 1, 1-17. [CrossRef]

6. Austin, I.G.; Mott, N.F. Polarons in crystalline and non-crystalline materials. Adv. Phys. 1969, 18, 41-102. [CrossRef]

7. Mackenzie, J.D.; Nasu, H. The electrical conductivity of transition metal oxide-based glasses. In Physics of Disordered Materials; Adler, D., Ed.; Plenum Press: New York, NY, USA, 1985; pp. 469-482.

8. Murawski, L.; Chung, C.H.; Mackenzie, J.D. Electrical properties of semiconducting oxide glasses. J. Non-Cryst. Solids 1979, 32, 91-104. [CrossRef]

9. Moguš-Milanković, A.; Day, D.E.; Šantić, B. DC conductivity and polarisation in iron phosphate glasses. Phys. Chem. Glasses 1999, 40, 69-74.

10. Šantić, A.; Moguš-Milanković, A. Charge carrier dynamics in materials with disordered structures: A case study of iron phosphate glasses. Croat. Chem. Acta 2012, 85, 245-254. [CrossRef]

11. Garbarczyk, J.E.; Jozwiak, P.; Wasiucionek, M.; Nowinski, J.L. Enhancement of electrical conductivity in lithium vanadate glasses by nanocrystallization. Solid State Ion. 2004, 175, 691-694. [CrossRef]

12. Garbarczyk, J.E.; Jozwiak, P.; Wasiucionek, M.; Nowinski, J.L. Effect of nanocrystallization on the electronic conductivity of vanadate-phosphate glasses. Solid State Ion. 2006, 177, 2585-2588. [CrossRef]

13. Garbarczyk, J.E.; Jozwiak, P.; Wasiucionek, M.; Nowinski, J.L. Nanocrystallization as a method of improvement of electrical properties and thermal stability of $\mathrm{V}_{2} \mathrm{O}_{5}$-rich glasses. J. Power Sources 2007, 173, 743-747. [CrossRef]

14. Pietrzak, T.K.; Garbarczyk, J.E.; Gorzkowska, I.; Wasiucionek, M.; Nowinski, J.L.; Gierlotka, S.; Jozwiak, P. Correlation between electrical properties and microstructure of nanocrystallized $\mathrm{V}_{2} \mathrm{O}_{5}-\mathrm{P}_{2} \mathrm{O}_{5}$ glasses. J. Power Sources 2009, 194, 73-80. [CrossRef]

15. Garbarczyk, J.E.; Pietrzak, T.K.; Wasiucionek, M.; Kaleta, A.; Dorau, A.; Nowinski, J.L. High electronic conductivity in nanostructured materials based on lithium-iron-vanadate-phosphate glasses. Solid State Ion. 2014, 272, 53-59. [CrossRef]

16. Pietrzak, T.K.; Wasiucionek, M.; Michalski, P.P.; Kaleta, A.; Garbarczyk, J.E. Highly conductive cathode materials for Li-ion batteries prepared by thermal nanocrystallization of selected oxide glasses. Mater. Sci. Eng. B 2016, 213, 140-147. [CrossRef]

17. Pavić, L.;Skoko, Ž.; Gajović, A.; Su, D.; Moguš-Milanković, A. Electrical transport in iron phosphate glass-ceramics. J. Non-Cryst. Solids 2018, 505, 44-53. [CrossRef] 
18. Moguš-Milanković, A.; Sklepić, K.; Skoko, Ž.; Mikac, L.; Musić, S.; Day, D.E. Influence of nanocrystallization on the electronic conductivity of zinc iron phosphate glass. J. Am. Ceram. Soc. 2012, 95, 303-311. [CrossRef]

19. Wu, C.-M.; Naseem, S.; Chou, M.-H.; Wang, J.-H.; Jian, Y.-Q. Recent Advances in Tungsten-Oxide-Based Materials and Their Applications. Front. Mater. 2019, 27, 49. [CrossRef]

20. Poirier, G.; Cassanjes, F.C.; Messadeq, Y.; Ribeiro, S.J. Crystallization of monoclinic $\mathrm{WO}_{3}$ in tungstate fluorophosphate glasses. J. Non-Cryst. Solids 2009, 35, 441-446. [CrossRef]

21. Poirier, G.; de Araujo, C.C.; Messadeq, Y.; Ribeiro, S.J. Tungsten fluorophosphate glass as optical limiters. J. Appl. Phys. 2002, 9, 100221-100223.

22. Poirier, G.; Nalin, M.; Messadeq, Y.; Ribeiro, S.J. Photochromic properties of tungstate-based glasses. Solid State Ion. 2007, 178, 871-875. [CrossRef]

23. Schlenker, C.; Le Touze, C.; Hess, C.; Rotger, A.; Dumas, J.; Marcus, J.; Greenblatt, M.; Teweldemedhin, Z.S.; Ottolenghi, A.; Foury, P.; et al. Transport properties of the charge density wave quasi two-dimensional compounds $\left(\mathrm{PO}_{2}\right)_{4}\left(\mathrm{WO}_{3}\right)_{2 \mathrm{~m}}$. Synth. Met. 1995, 70, 1263-1266. [CrossRef]

24. Roussel, P.; Labbe, P.H.; Groult, D. Symmetry and twins in the monophosphate tungsten bronze series $\left(\mathrm{PO}_{2}\right)_{4}\left(\mathrm{WO}_{3}\right)_{2 \mathrm{~m}}(2 \leq \mathrm{m} \leq 14)$. Acta Crystallogr. B 2000, 56, 377-391. [CrossRef] [PubMed]

25. Roussel, P.; Perez, O.; Labbe, P.H. Phosphate tungsten bronze series: Crystallographic and structural properties of low-dimensional conductors. Acta Crystallogr. B 2001, 57, 603-632. [CrossRef] [PubMed]

26. Aitken, B.G. Conductive $\mathrm{WO}_{3-\mathrm{x}}$ glass-ceramics. In The Physics of Non-Crystalline Solids; Pye, L.D., LaCourse, W.C., Stevens, H.J., Eds.; Taylor \& Francis: London, UK, 1992; pp. 548-552.

27. Salje, E.; Guttler, B. Anderson transition and intermediate polaron formation in $\mathrm{WO}_{3-\mathrm{x}}$ : Transport properties and optical absorption. Philos. Mag. B 1984, 50, 607-620. [CrossRef]

28. Moore, L.; Dutta, I.; Wheaton, B.; Stapleton, E.; Parysek, P.; Aitken, B. A new identification of the conducting phase in tungsten-titanium-phosphate glass-ceramics. J. Am. Ceram. Soc. 2020, 103, 3552-3651. [CrossRef]

29. Nikolić, J.; Pavić, L.; Šantić, A.; Mošner, P.; Koudelka, L.; Pajić, D.; Moguš-Milanković, A. Novel insights into electrical transport mechanism in ionic-polaronic glasses. J. Am. Ceram. Soc. 2018, 101, 1221-1235. [CrossRef]

30. Pavić, L.; Šantić, A.; Nikolić, J.; Mošner, P.; Koudelka, L.; Pajić, D.; Moguš-Milanković, A. Nature of mixed electrical transport in $\mathrm{Ag}_{2} \mathrm{O}-\mathrm{ZnO}-\mathrm{P}_{2} \mathrm{O}_{5}$ glasses containing $\mathrm{WO}_{3}$ and $\mathrm{MoO}_{3}$. Electrochim. Acta 2018, 276, 434-445. [CrossRef]

31. Pavić, L.; Nikolić, J.; Graça, M.P.F.; Costa, B.F.O.; Valente, M.A.; Skoko, Ž.; Šantić, A.; Moguš-Milanković, A. Effect of controlled crystallization on polaronic transport in phosphate-based glass-ceramics. Int. J. Appl. Glass Sci. 2020, 11, 97-111. [CrossRef]

32. Momma, K.; Izumi, F. VESTA 3 for three-dimensional visualization of crystal, volumetric and morphology data. J. Appl. Crystallogr. 2011, 44, 1272-1276. [CrossRef]

33. Šubčík, J. Study of Structure and Properties of Phosphate Glasses Modified by Heavy Metal Oxides. Ph.D. Thesis, University of Pardubice, Pardubice, Czech Republic, 2010.

34. Kierkegaard, P.; Asbrink, S. The Crystal Structure of $\mathrm{W}_{2} \mathrm{O}_{3}\left(\mathrm{PO}_{4}\right)_{2}$. Determination of a Superstructure by Means of Least-Squares Calculations. Acta Chem. Scand. 1964, 18, 2329-2338. [CrossRef]

35. Tanisaki, S. On the Phase Transition of Tungsten Trioxide below Room Temperature. J. Phys. Soc. Jpn. 1960, 15, 566-573. [CrossRef]

36. Hanawa, M.; Imoto, H. Structures of Two New Polymorphic Forms of Hexavalent Tungsten Oxide Phosphates. J. Solid State Chem. 1999, 144, 325-329. [CrossRef]

37. Mardare, C.C.; Hassel, A.W. Review on the Versatility of Tungsten Oxide Coatings. Phys. Status Solidi A 2019, 216, 1900047. [CrossRef]

38. Wang, C.; Yin, L.; Zhang, L.; Xiang, D.; Gao, R. Metal Oxide Gas Sensors: Sensitivity and Influencing Factors. Sensors 2010, 10, 2088-2106. [CrossRef] [PubMed]

39. Wang, S.-J.; Wang, M.-C.; Chen, S.-F.; Li, Y.-H.; Shen, T.-S.; Bor, H.-Y.; Wei, C.-N. Electrical and Physical Characteristics of $\mathrm{WO}_{3} / \mathrm{Ag} / \mathrm{WO}_{3}$ Sandwich Structure Fabricated with Magnetic-Control Sputtering Metrology. Sensors 2018, 18, 2803. [CrossRef] [PubMed]

40. Gillet, M.; Lemire, C.; Gillet, E.; Aguir, K. The role of surface oxygen vacancies upon $\mathrm{WO}_{3}$ conductivity. Surf. Sci. 2003, 532, 519-525. [CrossRef]

41. Khyzhum, O.Y. XPS, XES and XAS studies of the electronic structure of tungsten oxides. J. Alloys Compd. 2000, 305, 1-6. [CrossRef] 
Publisher's Note: MDPI stays neutral with regard to jurisdictional claims in published maps and institutional affiliations.

(c)

(C) 2020 by the authors. Licensee MDPI, Basel, Switzerland. This article is an open access article distributed under the terms and conditions of the Creative Commons Attribution (CC BY) license (http://creativecommons.org/licenses/by/4.0/). 